\title{
Chapter 6 \\ New Approach for Bearing Life Cycle Estimation and Control
}

\author{
Eneko Olabarrieta, Egoitz Konde, Enrique Guruceta \\ and Mikel Armendia
}

\subsection{Introduction}

Machine tools are usually composed by several main elements with relative movements among them. In order to minimize friction losses, different types of bearing technologies have been applied: sliding contact, rolling, hydrostatic, aerostatic and magnetic. Among them, rolling technology has the leading position due to the best combination of performance, cost and reliability [1]. However, these elements are meant to be worn and, indeed, their failure is one of the most critical issues for machine tool reliability [2].

Rolling technology can be applied for both rotational (bearings) and linear (guideways) movements. It can be even applied to rotational-to-translational movement conversion elements like rolling screw drives. Since the first patent related to bearings was published in the eighteenth century, these mechanical components have been widely used in almost every engineering field and they continue being a proper mechanical solution to a vast variety of design challenges. Thus, the improvements in engineering theoretical and experimental tools and more efficient industry processes have led to the need to perform exhaustive research on bearing life prediction methodologies.

\author{
E. Olabarrieta $(\bowtie) \cdot$ E. Konde $\cdot$ E. Guruceta $\cdot$ M. Armendia \\ IK4-Tekniker, C/ Iñaki Goenaga, 5, 20600 Eibar, Gipuzkoa, Spain \\ e-mail: eneko.olabarrieta@tekniker.es \\ E. Konde \\ e-mail: egoitz.konde@tekniker.es \\ E. Guruceta \\ e-mail: enrique.guruceta@tekniker.es \\ M. Armendia \\ e-mail: mikel.armendia@tekniker.es \\ (C) The Author(s) 2019 \\ M. Armendia et al. (eds.), Twin-Control, \\ https://doi.org/10.1007/978-3-030-02203-7_6
}


Bearing life estimation theories started on nineteenth century with the testing of rolling bearings performed by Stribeck [3]. Goodman [4] and Palmgren [5] continued the work on the twentieth century by introducing the important concept of fatigue limit in rolling bearing life. A new milestone was set by Weibull [6] with his statistical theory of the strength of materials and, in the 60s, Lundberg and Palmgren [7, 8] presented their life theory of rolling bearings. This was the basis for the current L10 formula [9] for the basic rating life of rolling bearing. Moreover, more accurate testing methods and complex analysis tools have let the researchers improve the rating life estimations, and the modified rating life [9] has become a powerful tool for better life predictions, taking into account aspects like oil condition or fatigue load.

Anyway, the deterministic prediction of the initiation of a failure in a specific bearing is impossible. For fatigue damages, bearing diagnostics is a powerful tool for avoiding undesired failures. Furthermore, if a bearing presents some evidence of wear instead of rolling contact fatigue, the lifetime cannot be mathematically predicted on a statistical basis [10].

The presented activity does not pretend the development of a new wear model that improves the performance of well-known references like the ones presented in the ISO 281 [9], but to present an approach that can facilitate the analysis to the end user and can be combined with other data sources to improve end-of-life estimations. The work is focused on bearings performance, but it can be easily extrapolated with other rolling-based elements like guideways and screw drives.

This work is composed of five sections. The first one presents the introduction and context of this research. The second one presents the background of the proposed approach. The third chapter introduces the developed calculation module and proposes a new approach for bearings lifecycle study. Next, a summary of the results obtained in experimental tests is provided. Finally, the conclusions are presented.

\subsection{Theoretical Background}

As mentioned, the aim of this work is not to determine a new model for bearing endof-life calculation, but to use the existing theoretical standardized background [9] to implement it in a more efficient way. The objective is to avoid doing conservative estimations of the loads and replace them by more accurate estimations based on the results provided by a powerful simulation tool [11].

When a specific bearing (or bearing combination) is selected for an application, life must be estimated in order to analyze its suitability regarding the load characteristics of the whole system. Thus, preliminarily, the basic rating life $\left(L_{10 h}\right)$ is used. The following simple and well-known formula represents the life of the bearing in hours [9]:

$$
L_{10 h}=\frac{10^{6}}{60 \cdot n}\left(\frac{C}{P}\right)^{p}
$$


where $n$ is the rotating speed, $C$ is the dynamic radial load capacity of the bearing with a $90 \%$ of reliability, $P$ is the equivalent load and $p$ is an exponent defined by the bearing type.

This simple operation gives to the designer a general idea of the performance of the bearing, but it has been shown that it is a quite conservative estimation. A more accurate estimation can be obtained by applying the modified life rating $\left(L_{\mathrm{nmh}}\right)$, which includes bearing operating conditions (lubrication, temperature, etc.) in the estimations.

$$
L_{\mathrm{nmh}}=a_{1} \cdot a_{\mathrm{ISO}} \cdot L_{10 h}
$$

where $a_{1}$ is the reliability factor and $a_{\mathrm{ISO}}$ is the life modification factor, which depend on the usage conditions (oil contamination level and viscosity) and the limit load regarding fatigue.

The load capacity $C$ is determined both experimentally and analytically and is always provided by the manufacturer. However, the equivalent load $P$ is more complex to calculate. The following basic formulation is used for that purpose in individual bearings:

$$
P=X \cdot F_{r}+Y \cdot F_{a}
$$

where $X$ is the radial load factor, $Y$ is the axial load factor and $F_{r}$ and $F_{a}$ are the average radial and axial loads actuating on the bearing. The factors are given by the bearing characteristics, and the average loads must be estimated from the correspondent application through calculations or measurements.

In most applications, load and speed conditions vary in time. To take into account, these time-dependent effects, equivalent rotating speed and loads must be considered. Thus, the equivalent values are computed as follows:

- Speed:

$$
n_{e}=\sum_{1}^{N} n_{i} \cdot \frac{\Delta t_{i}}{100}
$$

- Load:

$$
F_{\mathrm{re}}, F_{\mathrm{ae}}=\sum_{1}^{N} F_{i} \cdot \frac{n_{i}}{n_{e}} \cdot \frac{\Delta t_{i}}{100}
$$

where $N$ is the number of samples of the vector, $\Delta t_{i}$ the sampling rate, $n_{i}$ and $F_{i}$ the speed and load, respectively, at sample i, $n_{e}$ the equivalent speed and $F_{\text {re }}$ and $F_{\text {ae }}$, the equivalent radial and axial loads, respectively. 


\subsection{End-of-Life Calculation Module}

Considering the previous formulation (Eqs. 6.1-6.5), a rating life calculation module has been set-up in MATLAB environment. Currently, the module calculates an endof-life value based on bearing characteristics (type, load capacity and dimensions), applied loads and operating conditions (reliability, cleanliness, temperature and oil type). In order to facilitate the configuration to the end user, the module includes a bearing database. By selecting the bearing references, required bearing characteristics are automatically loaded in the module. With the defined inputs, the module provides both the basic rating life (in revolutions and hours) and the modified rating life (in hours) that considers the operating conditions. The proposed calculation module can enhance bearing analysis at two stages (Fig. 6.1).

In the machine tool design stage, the module can calculate end-of-life based on loads provided by a machine tool simulation module [11-13] that can provide very accurate component loads. The possibility to use an accurate input to the end-oflife module will, of course, enhance the life predictions and, hence, machine tool designers will be able to select more suitable bearing. Figure 6.2 presents the module integrated in the Twin-Control application, with two interfaces for the configuration and results visualization.

In the machine tool usage stage, thanks to the current $\mathrm{NC}$ monitoring capabilities, real component loads can be derived, without the need of expensive and complex bearing monitoring sensors. This allows the estimations of the remaining useful life of the studied component. In Twin-Control project, the end-of-life module has been integrated in KASEM, the fleet management system provided by PREDICT (Fig. 6.3). Remaining useful data is calculated periodically using real usage conditions monitored and uploaded thanks to the ARTIS hardware installed in the machine.

Equations defined in the ISO 281 standard [9] are based on ideal usage conditions, the ones used for the calculation. However, the real usage of a machine is not ideal and the results provided by the module may not be valid after certain uncontrolled events (e.g., collisions). Because of this, remaining useful life estimations should be combined with condition monitoring using vibration sensors to detect performance change in the bearings.

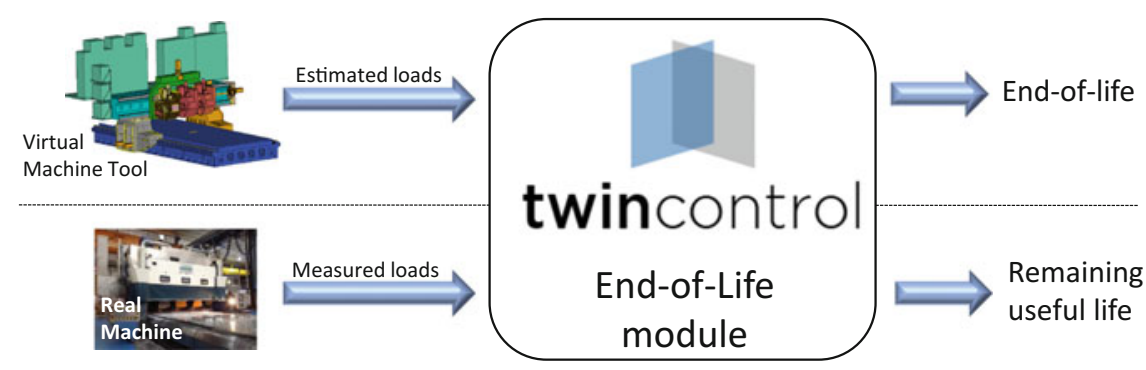

Fig. 6.1 Bearing lifecycle analysis approach 
(a)

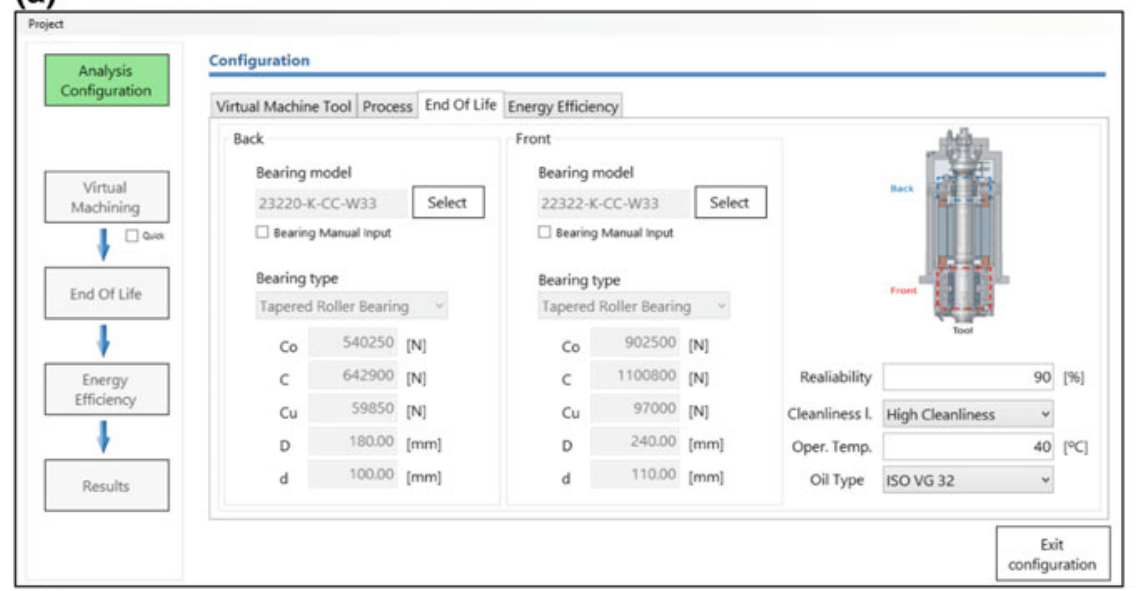

(b)

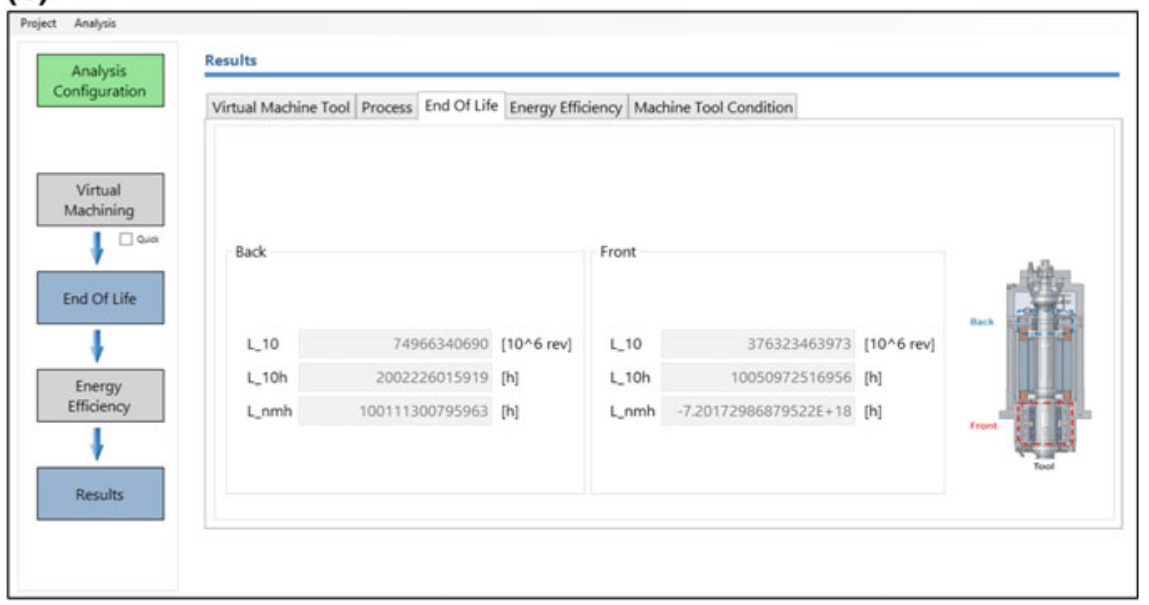

Fig. 6.2 Screenshots of the end-of-life module implemented in the main Twin-Control simulation application: a Configuration tab; b Results tab

\subsection{Validation Tests}

\subsubsection{Experimental Set-up}

For validation purposes, trials in a special test bench for testing rolling bearings that is available at IK4-TEKNIKER will be used (Fig. 6.4). This test bench provides the possibility to apply axial loads to the bearings while they are rolling at a certain speed. 
(a)

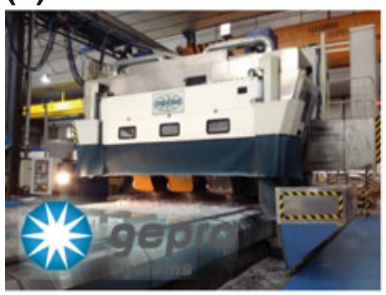

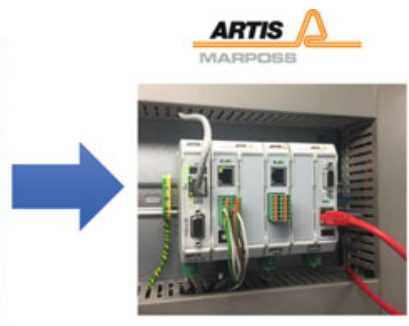

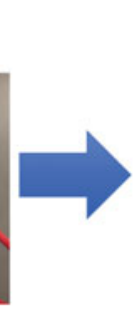

(b)

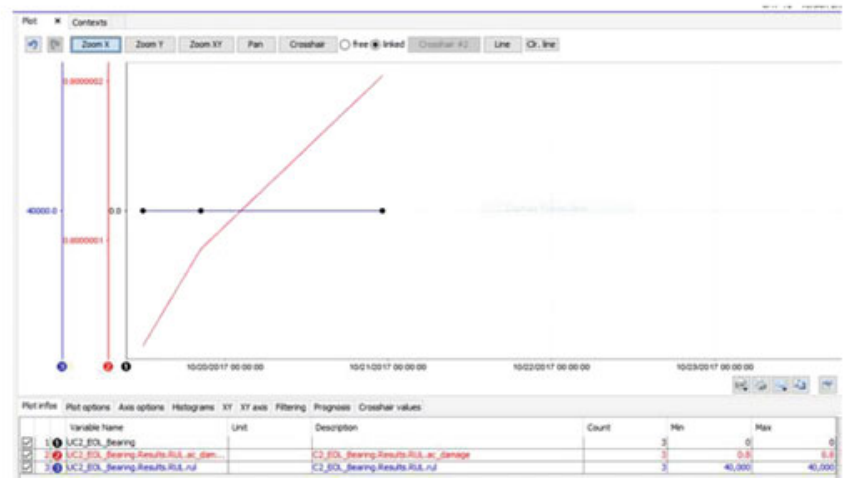

Fig. 6.3 Remaining useful life module: a Approach followed in Twin-Control; $\mathbf{b}$ Example of results of the front spindle of a GEPRO 502 machine

The FALEX test bench has a complete monitoring infrastructure, including force, speed, temperature and vibration sensors and a National Instruments cDAQ acquisition system.

Bearing wear is normally a long duration phenomenon. To adapt test duration and be able to analyze results in an affordable period, accelerated wear tests have been performed by selecting a bearing that provides an end-of-life below $24 \mathrm{~h}$ with the loads that can be applied by the test bench ( $10 \mathrm{kN}$ axial static force at $10,000 \mathrm{rpm})$.

A SKF $71908 \mathrm{CB} / \mathrm{HCP} 4 \mathrm{AL}$ angular contact ball bearing will be used for the accelerated tests, which is a smaller version of the bearings typically used in machine tool spindles. A special-purpose fixture has been specifically designed and manufactured to host this bearing (Fig. 6.5). The fixture allows internal water cooling and the application of different lubrication types: dry, air/oil, grease and oil. The fixture also permits the installation of embedded temperature and vibration sensors.

A total of 6 bearings have been tested. For the proposed bearing, the calculation module estimated a nominal end-of-life of $7 \mathrm{~h}$, while the modified end-of-life, applying the test conditions, is $15 \mathrm{~h}$. The conditions used in the tests were $4 \mathrm{kN}$ of static axial load and $6200 \mathrm{rpm}$ of rotation speed. 


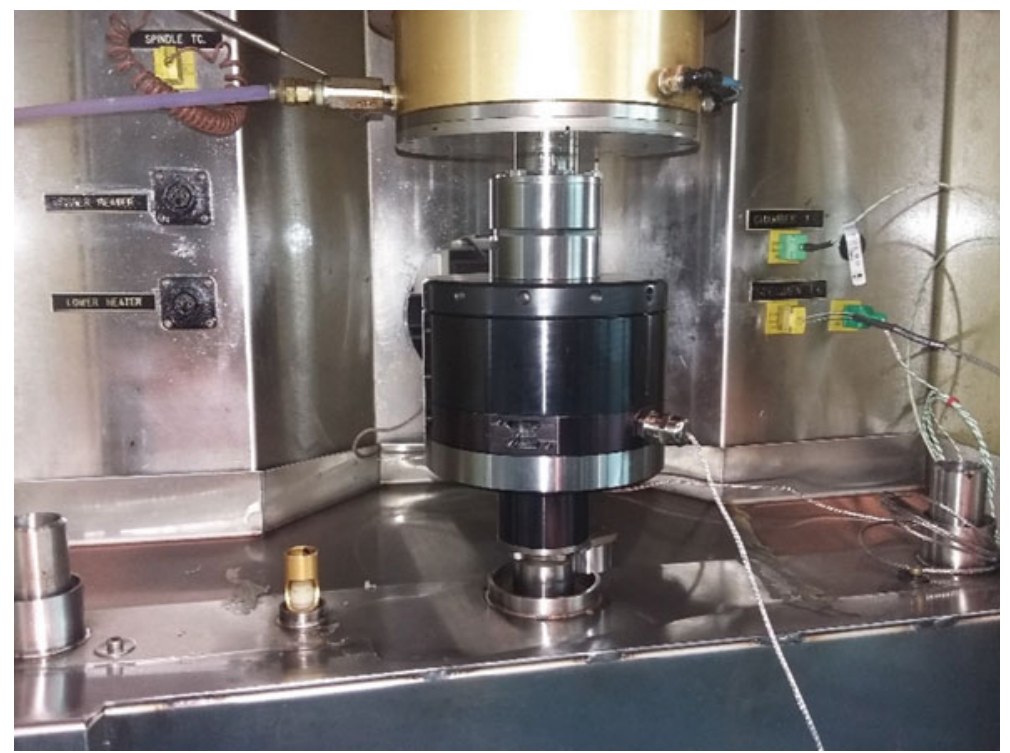

Fig. 6.4 FALEX test bench available at IK4-TEKNIKER installations

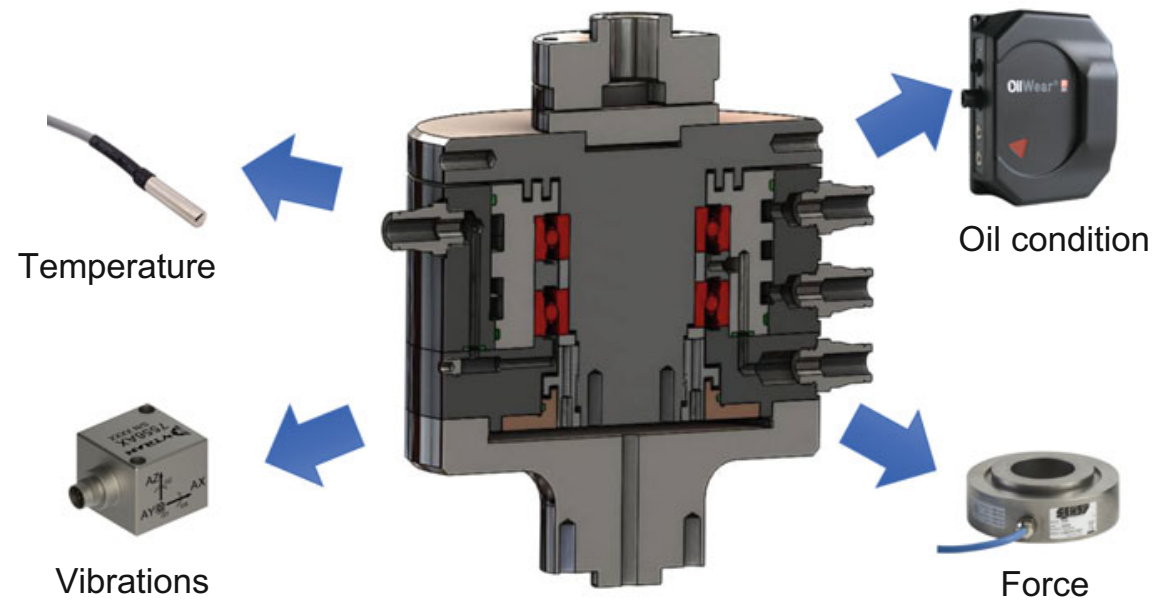

Fig. 6.5 Cross section of the design of the special fixture manufactured for the accelerated tests of the selected bearings (in red) 
Table 6.1 Summary of the experimental tests ( $4 \mathrm{kN}$ of static axial load and $6200 \mathrm{rpm}$ of rotation speed)

\begin{tabular}{l|l|l|l}
\hline$\#$ & Test stop time $(\mathrm{h})$ & Failure & Comments \\
\hline 1 & 22 & Greasing & - \\
\hline 2 & 34 & Pitting & Regreasing after $20 \mathrm{~h}$ \\
\hline 3 & 20 & - & Good condition \\
\hline 4 & 23 & Greasing & - \\
\hline 5 & 18 & Severe pitting & - \\
\hline 6 & 35 & Micro-pitting & Regreasing every $5 \mathrm{~h}$ \\
\hline
\end{tabular}

(a)

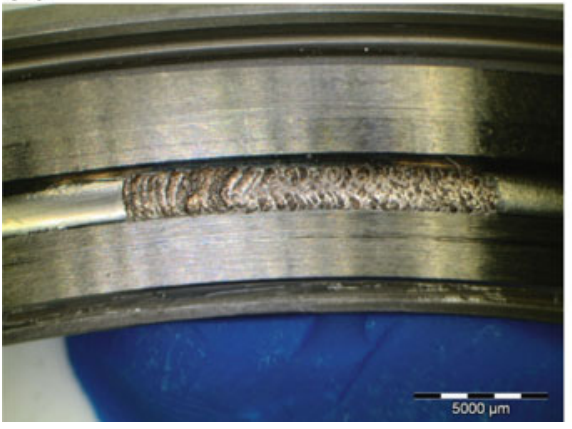

(b)

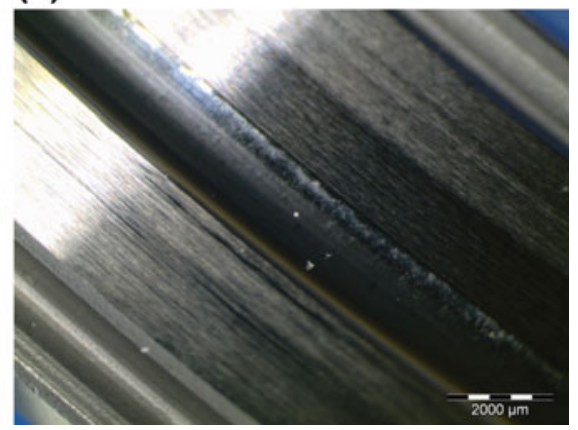

Fig. 6.6 Microscope images showing outer rings of the bearings: a \#5 with severe pitting after $18 \mathrm{~h}$; b \#6 with micro-pitting after $35 \mathrm{~h}$ (with a regreasing every $5 \mathrm{~h}$ )

\subsubsection{Results}

Table 6.1 summarizes the results of the experimental tests. A big variance of end-oflife is observed, but always above the value determined by the calculation using the ISO 281 standard [9].

When analyzing the wear mechanism, lack of grease seemed to be the main problem, leading to pitting (Fig. 6.6) in the outer ring of the bearings. For these reasons, some of the tests were stopped after some time for a regreasing. By doing this, an extension of the end-of-life was observed.

\subsubsection{Vibration Measurements}

Figure 6.7 shows the evolution of the root mean square (RMS) in the whole studied frequency range $(10-2000 \mathrm{kHz})$ of the vibration signal acquired during test \#5. A sudden increase of vibration is observed at around $14 \mathrm{~h}$, clear indicator that the bearing started to fail. The test continued until $18 \mathrm{~h}$, showing a totally worn condition 


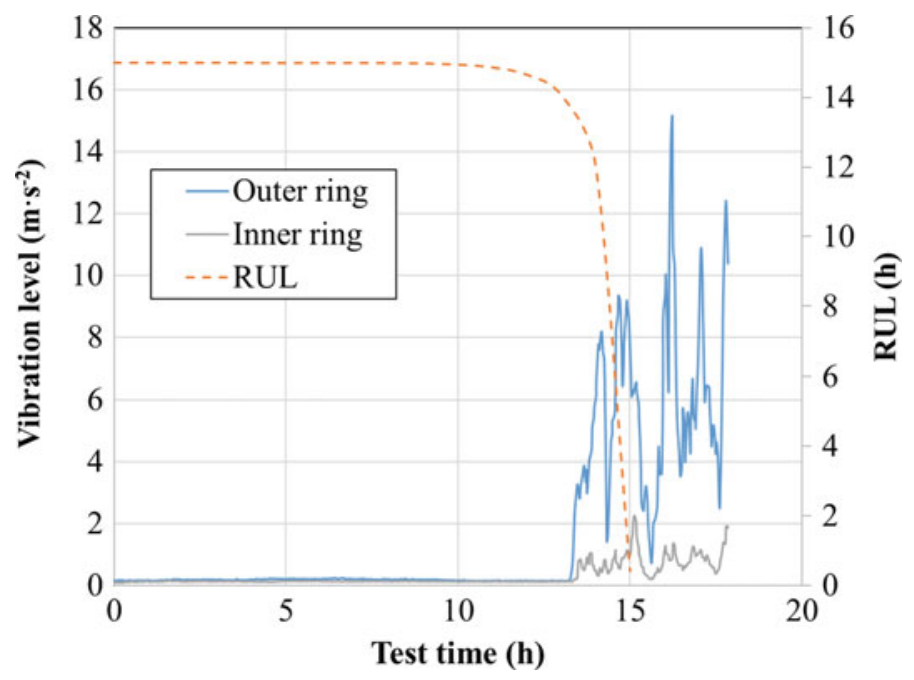

Fig. 6.7 RMS of the global vibration signal measured during test \#5. Theoretical RUL evolution is plotted in dotted line

(Fig. 6.6a). The evolution of the theoretical remaining useful life (RUL) calculated for this bearing using the simulation module based on the ISO 281 standard is also presented.

The analysis of the frequency bands of interest for the selected bearing provides additional knowledge. An envelope analysis is applied in the frequency bands corresponding to the outer $(1333 \mathrm{~Hz})$ and inner rings $(1560 \mathrm{~Hz})$. Looking at the results obtained in test \#5 again, bearing wear initiation can be detected where the vibration level at these bands increases (Fig. 6.8). In addition, it can be observed that higher vibration levels are measured in the frequency band corresponding to the outer ring, the one showing higher wear after visual inspection (Fig. 6.6).

\subsection{Conclusions}

A new approach for the study of bearing lifecycle performance is presented. The proposed approach is based on the well-known ISO 281 for end-of-life determination. The work is focused on bearings performance, but it can be easily extrapolated with other rolling-based elements like guideways and screw drives.

A specific tool has been developed that calculates the end-of-life of a specific bearing for a defined load cycle (forces and speeds in time). This tool allows bearing analysis through all its lifecycle. On the one hand, the module can be used in machinery design stage by providing an improved estimation of end-of-life by using load variation in time during the manufacturing cycle. This will allow a better selection 


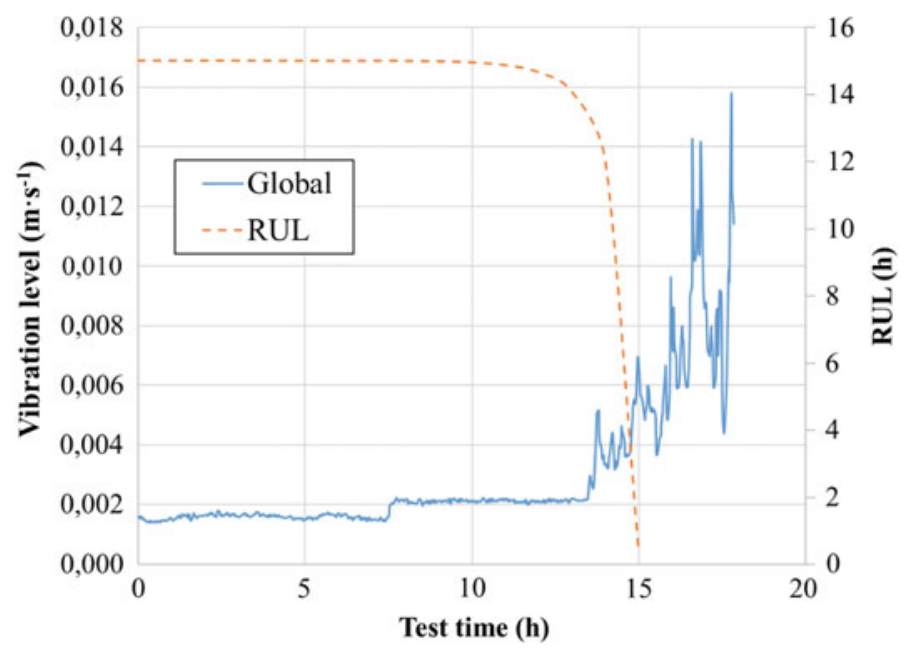

Fig. 6.8 Vibration level obtained applying envelope analysis to the frequency ranges corresponding to the outer and inner rings of the selected bearing (test \#5). Theoretical RUL evolution is plotted in dotted line

of the critical components. On the other hand, the tool is prepared to be fed by real machine usage data (monitored). This way, remaining useful life of a component can be provided. In parallel, the usage of a condition monitoring system based on vibration measurement can be used to detect anomalous performance (out of the nominal behavior, like collisions).

Some preliminary validation tests have been done in a test bench available in IK4TEKNIKER installations. The tests showed that the ISO standard underestimates the end-of-life of components. In addition, results provided by the vibration measurements showed the possibility to detect component failure in an early stage. This early detection will allow more efficient maintenance actions in industrial applications.

The proposed approach is aligned with some concepts aligned with current trends in ICT technologies: combination of different simulation models to improve estimations and integration of simulation models with monitored data to control system performance.

\section{References}

1. Sutar, M.D., Deshmukh, B.B.: Linear motion guideways-a recent technology for higher accuracy and precision motion of machine tool. Int. J. Innovations Eng. Technol. 3(1) (2013)

2. Fleischer, J., Broos, A., Schopp, M., Wieser, J., Hennrich, H.: Lifecycle-oriented component selection for machine tools based on multibody simulation and component life prediction. CIRP J. Manuf. Sci. Technol. 1(3) (2009) 
3. Stribeck, R.: Kugellager fü $\mathrm{r}$ beliebige Belastungen. Zeitschrift des Vereines deutscher Ingenieure 45(3), 73-9 (pt I) \& 45(4), 118-125 (pt II)

4. Goodman, J.: Roller and ball bearings. Proc. Inst. Civil Eng. 189, 82-166 (1912)

5. Palmgren, A.: Ball and Roller Bearing Engineering, First edn., (trans.: Palmgren, G., Ruley, B). SKF Industries, Inc., Philadelphia, PA (1945)

6. Weibull, W.: A statistical theory of the strength of materials. In: Proceedings of the Royal Swedish Academy of Engineering Sciences, 45 pp., vol. 151, Stockholm, Sweden (1939)

7. Lundberg, G., Palmgren, A., Dynamic capacity of rolling bearings. In: Proceedings of the Royal Swedish Academy of Engineering Sciences, 50 pp., vol. 196, Stockholm, Sweden (1947)

8. Lundberg, G., Palmgren, A.: Dynamic capacity of roller bearings. In: Proceedings of the Royal Swedish Academy of Engineering Sciences, 32 pp., vol. 210, Stockholm, Sweden (1952)

9. ISO 281:2007: Rolling bearings-Dynamic load ratings and rating life

10. Halme, J., Andersson, P.: Rolling contact fatigue and wear fundamentals for rolling bearing diagnostics—state of the art. Proc. Inst. Mech. Eng. Part J: J. Eng. Tribol. 224(4) (2010)

11. Cugnon, F., Berglind, L., Plakhotnik, D., Ozturk, E.: Advance modelling of machine tool machining process. In: ECCOMAS Conference 2017, Prague, 19-22 June 2017

12. Gugnon, F., Ghasempouri, M., Armendia, M.: Machine tools mechatronic analysis in the scope of Twin-Control project. In: NAFEMS World Congress 2017, Stockholm, 11-14 June 2017

13. Berglind, L., Plakhotnik, D., Ozturk, E.: Discrete cutting force model for 5-axis milling with arbitrary engagement and feed direction. Procedia CIRP 58, 445-450 (2017)

Open Access This chapter is licensed under the terms of the Creative Commons Attribution 4.0 International License (http://creativecommons.org/licenses/by/4.0/), which permits use, sharing, adaptation, distribution and reproduction in any medium or format, as long as you give appropriate credit to the original author(s) and the source, provide a link to the Creative Commons license and indicate if changes were made.

The images or other third party material in this chapter are included in the chapter's Creative Commons license, unless indicated otherwise in a credit line to the material. If material is not included in the chapter's Creative Commons license and your intended use is not permitted by statutory regulation or exceeds the permitted use, you will need to obtain permission directly from the copyright holder.

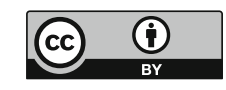

